\title{
Finite element modeling of geothermal source of heat pump in long-term operation
}

\author{
Elżbieta Hałaj $^{1 *}$ \\ ${ }^{1}$ AGH University of Science and Technology, Faculty of Geology, Geophysics and Environmental \\ Protection, A. Mickiewicza 30 Ave, 30-059 Krakow, Poland
}

\begin{abstract}
Heat pumps become more and more popular heat source. They can be an alternative choice for obsolete coal fired boilers which are emissive and not ecological. During heat pump installation designing process, especially for heat pumps with higher heating capacity (for example those suppling larger buildings), a simulation of heat balance of ground heat source must be provided.

A 3D heat transport model and groundwater flow in the geothermal heat source for heat pump (GSHP) installation was developed in FEFLOW according to Finite Element Modelling Method. The model consists of 25 borehole heat exchangers, arranged with spacing recommended by heat pump branch guidelines. The model consists of both a homogeneous, nonlayered domain and a layered domain, which reflected differences in thermal properties of the ground and hydrogeological factors. The initial temperature distribution in the ground was simulating according to conditions typical for Europe in steady state heat flow. Optimal mesh refinement for nodes around borehole heat exchangers were calculated according to Nillert method.

The aim of this work is to present influence of geological, hydrogeological factors and borehole arrangement in the energy balance and long term sustainability of the ground source. The thermal changes in the subsurface have been determined for a long term operation (30 years of operation period). Some thermal energy storage applications have also been considered.
\end{abstract}

\section{Introduction}

Geothermal source heat pumps are more and more popular these days. When borehole heat exchangers are installed, especially in close proximity, they can interfere each other and decrease efficiency of heat pump. Their operating regime is very important for sustainable long term operation.

\footnotetext{
* Corresponding author: elzbieta.halaj@gmail.com
} 
In order to compare different operating regimes different scenarios were taken into consideration:

1) parameters homogeneous, not balanced energy load (only heating in winter)

2) parameters homogeneous, balanced energy load (heating in winter and cooling in summer)

3) parameters according to different layers of the model, not balanced energy (only heating in winter)

The changes of the ground temperature were simulated over 30 years (ca. $260000 \mathrm{~h}$ ). The model area was situated in Central Poland. And an overall performance of multi BHE system is observed.

Typical lifetime of heat pump installations are ca. 20 years, while the heat sources (heat exchangers in the ground) are considered to have operational period of even 50 years.

\section{Model}

The model dimensions were set as $240 \times 240 \times 105 \mathrm{~m}$. In the area 25 borehole heat exchangers (BHE), each of $100 \mathrm{~m}$ length were set $10 \mathrm{~m}$ from each other. Non uniform grid for the area was used. In the vicinity of wells grid points were refined, to obtain better accuracy (Fig. 1). Optimal mesh refinement for nodes around BHEs were calculated according to Nillert method [1].

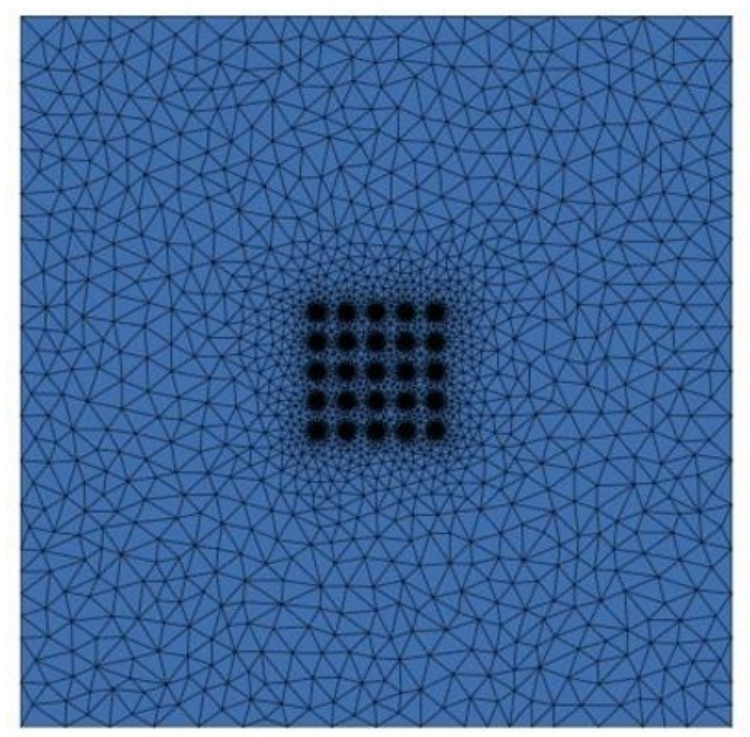

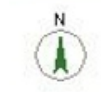

FEFLOW (R)

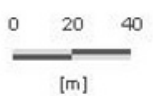

Fig. 1 Mesh geometry in the model.

Modelling of the heat and fluid flow was undertaken using FEFLOW Programme by DHI (MIKE Powered by DHI Software), which provide Finite Element Modelling of Flow, 
Mass and Heat Transport in Porous and Fractured Media. In FEFLOW a borehole solution is coupled with the rest of the model domain by the temperature at the nodes of the borehole [3].

In homogeneous model all layers have thickness of $10 \mathrm{~m}$. For layered model layers are arranged like shown in the Fig. 2. Parameters of borehole heat exchangers are given in Tab. 1. The Borehole heat exchanger is a boundary condition for heat transport of a lineshaped nature. The fixed power of BHEs were connected with time regime to obtain assumed energy (Tab. 2).

Tab. 1 Parameters of BHE

\begin{tabular}{|l|l|}
\hline Borehole length & $100 \mathrm{~m}$ \\
\hline Number of boreholes & 25 \\
\hline Borehole spacing & $10 \mathrm{~m}$ \\
\hline Total length of boreholes & $2500 \mathrm{~m}$ \\
\hline Borehole radius & $0.15 \mathrm{~m}$ \\
\hline Type of exchanger & Double U-shape \\
\hline
\end{tabular}

\section{Thermal and hydrogeological settings}

The model is considered as fully saturated. The initial heat condition across the model was set to $9^{\circ} \mathrm{C}$. Then, to show thermal regime, different heat flux from the ground during the year was set to the top surface according to change of the earth's surface monthly average temperature (Tab. 2) for the area of Central Poland. These values were set as boundary conditions of first kind. Moreover, geothermal heat flux assessed for this area as $0.06 \mathrm{~W} / \mathrm{m}^{2}$ was set to the base surface of the model.

Tab. 2 Average earth temperature in the study area [2] and energy load

\begin{tabular}{|l|c|c|}
\hline Month & $\begin{array}{c}\text { Earth's surface } \\
\text { temperature } \\
{\left[{ }^{\circ} \mathrm{C}\right]}\end{array}$ & $\begin{array}{c}\text { Average energy per BHE } \\
{[\mathrm{kWh}]}\end{array}$ \\
\hline I & -3.5 & 558 \\
\hline II & -2.2 & 504 \\
\hline III & 2.3 & 558 \\
\hline IV & 9.2 & 360 \\
\hline V & 15.3 & 186 \\
\hline VI & 18.3 & -180 (cooling, optional) \\
\hline VII & 20.9 & -372 (cooling, optional) \\
\hline VIII & 20.6 & -186 (cooling, optional) \\
\hline IX & 14.7 & 0 \\
\hline X & 8.6 & 186 \\
\hline XI & 1.8 & 540 \\
\hline XII & -2.5 & 558 \\
\hline
\end{tabular}

The BHE system was operating according to assessed monthly load as shown in Tab. 2 . The groundwater is flowing from the south to the north. More parameters are shown in Tab. 3. The parameters are estimated for values in the Central Poland conditions. 
Tab.3 Ground and water initial parameters

\begin{tabular}{|l|l|l|}
\hline \multicolumn{1}{|c|}{ Parameter } & \multicolumn{1}{|c|}{ Homogeneous model } & \multicolumn{1}{c|}{ Layered model } \\
\hline Porosity & 0.3 & $0.18-0.2 ; 0.3$ for aquifer \\
\hline $\begin{array}{l}\text { Volumetric heat capacity of } \\
\text { groundwater }\end{array}$ & $4.210^{6} \mathrm{~J} / \mathrm{m}^{3} / \mathrm{K}$ & $4.210^{6} \mathrm{~J} / \mathrm{m}^{3} / \mathrm{K}$ \\
\hline $\begin{array}{l}\text { Volumetric heat capacity of solid } \\
\text { phase }\end{array}$ & $2.5210^{6} \mathrm{~J} / \mathrm{m}^{3} / \mathrm{K}$ & $2.5210^{6} \mathrm{~J} / \mathrm{m}^{3} / \mathrm{K}$ \\
\hline $\begin{array}{l}\text { Thermal conductivity of } \\
\text { groundwater }\end{array}$ & $0.65 \mathrm{~W} / \mathrm{m} / \mathrm{K}$ & $0.65 \mathrm{~W} / \mathrm{m} / \mathrm{K}$ \\
\hline Thermal conductivity of solid phase & $2 \mathrm{~W} / \mathrm{m} / \mathrm{K}$ & according to layer \\
\hline Fluid flux & $4000 \mathrm{~mm} / \mathrm{a}$ & $4000 \mathrm{~mm} / \mathrm{a}$ in aquifer \\
\hline Groundwater conductivity & $2.510^{-4} \mathrm{~m} / \mathrm{s}$ & $\begin{array}{l}1.010^{-4} \mathrm{~m} / \mathrm{s} ; 2.510^{-4} \mathrm{~m} / \mathrm{s} \\
\text { for aquifer }\end{array}$ \\
\hline
\end{tabular}

The model is considered confined. Aquifers have good flow conditions. Fluid flows only from south to the north due to fixed fluid flux with speed limited by groundwater conductivity. Other borders are fixed as impermeable.

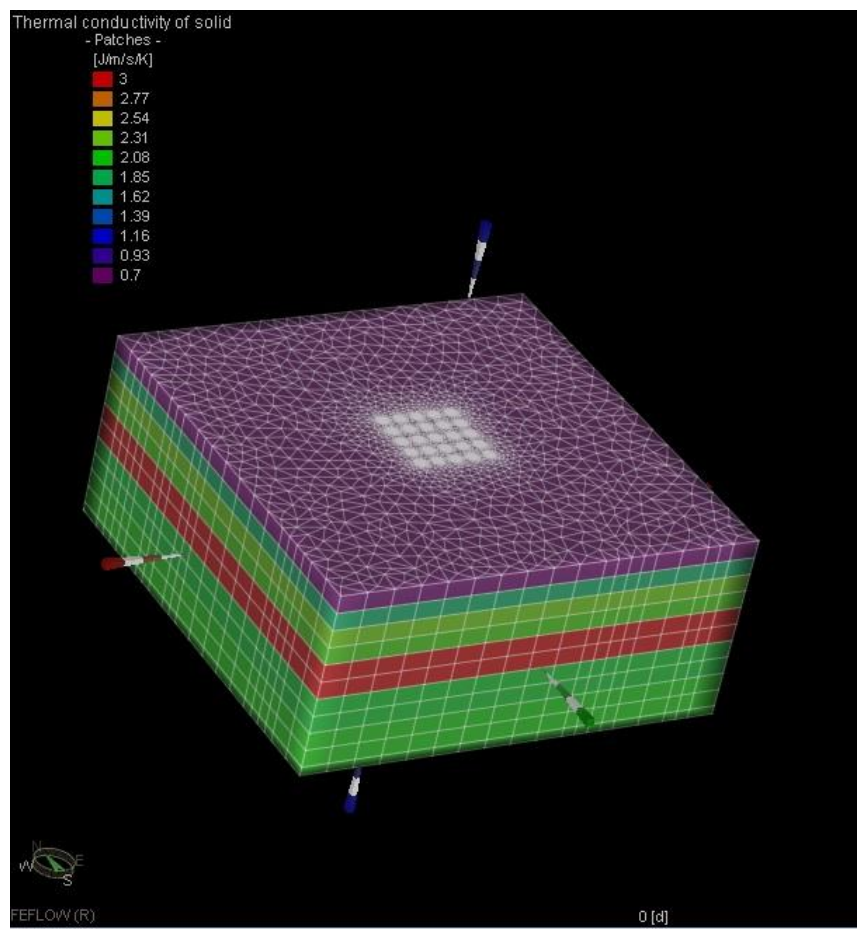

Fig. 2 Thermal conductivity in the layered model

\section{Results and conclusions}


Performance of the multi BHE system can be successfully modelled using Finite Element Modelling. The change in temperature of ground around BHEs can be observed during specific time span (Fig. 3).

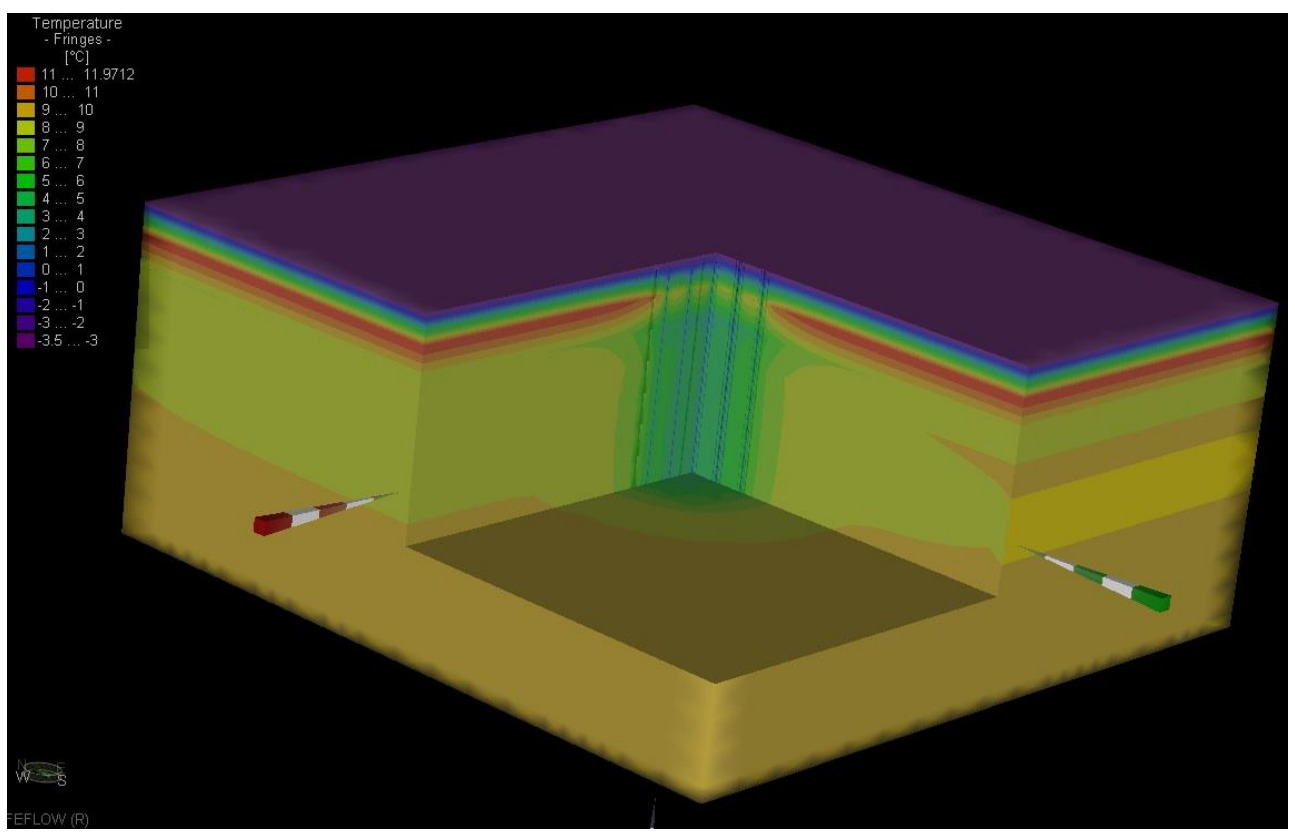

Fig. 3 3D model of temperature in the homogeneous ground after ca. 7 years of BHE system operation (layered model)

According to simulations, after 30 years temperature can drop significantly, even below $0^{\circ} \mathrm{C}$ (Fig. 4 A,B). These situation occurred in the winter heating only mode, when temperature of the ground drops to $-0.11^{\circ} \mathrm{C}$. Temperature of the refrigerant dropped then even to $-3.5{ }^{\circ} \mathrm{C}$ in several BHEs after 20 year of operation. However, later the drop of the temperature is not extreme and increase slowly. Good flow conditions of the aquifer cause temperature plum to travel according to fluid flux to the north, which cause changes to existing BHEs, but also can interfere BHEs performance that can be installed in the vicinity in the future.

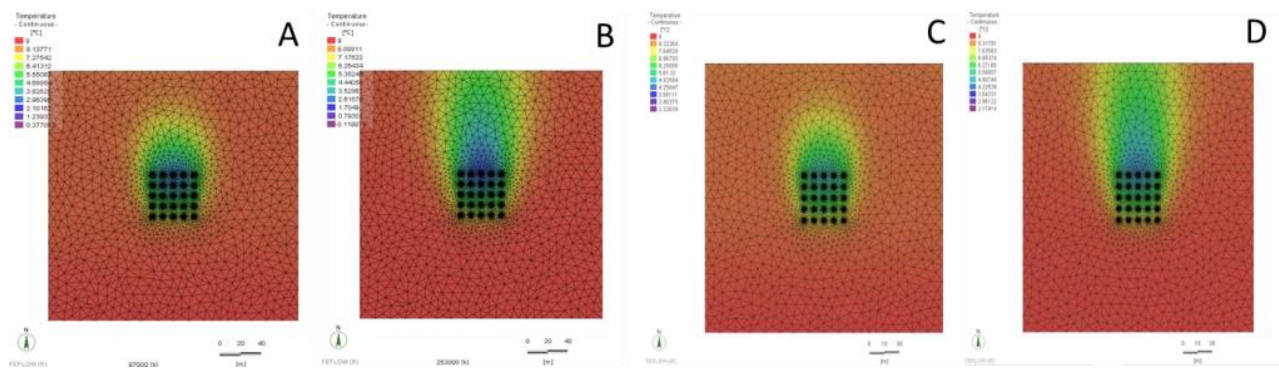


Fig. 42 D model of temperature in the ground (depth of $50 \mathrm{~m}$ ) after 10 (A) and 30(B) years of BHE operation without storage and after 10 (C) and 30 (D) years of BHE operation with energy storage during summer (homogeneous model)

Some improvement of the ground temperature value can be done by considering thermal energy storage or at least seasonal energy storage from space cooling or other sources (Fig. 4 C,D). After 30 years of operation temperature of the ground doesn't drop below $2{ }^{\circ} \mathrm{C}$, while temperature of refrigerant doesn't drop below $-1.5^{\circ} \mathrm{C}$ in the ,coldest” BHE. BHE positions rearrangements are also suggested. The number of heat pump installations is increasingly growing. The ground with higher water flow has the further range of thermal changes regime, which can be crucial in considering further installation in the vicinity.

Geological and hydrogeological conditions have a great impact to the BHE system performance. Thus, good recognition of parameters and suitable long-term simulation are necessary installing a sustainable ground sources for heat pumps. Installations with seasonal storage (if possible) are preferred for long time operation due to better ground thermal recovery which causes higher effectiveness of heat pumps installation and prevents ground freezing. FEM modelling of such installations would answer a question if a given heat pump and BHE installation can work efficiently in specific conditions and location of installation.

This research was supported by DHI by making the mentioned MIKE Powered by DHI Software available for the research. I would thank DHI for support. Although they may not agree with all of the interpretations/conclusions of this paper. Article prepared under AGH University of Science and Technology statutory work No. 16.16.140.315.

\section{References}

1. H.-J. Diersch, FEFLOW - Finite Element Modelling of Flow, Mass and Heat Transport in Porous and Fractured Media (Springer-Verlag Berlin Heidelberg, 2014)

2. NASA - NASA's Satellite provided for use with the RETScreen Software via the NASA Prediction of Worldwide Energy Resource (POWER) project

3. S. E. Dehkordi et al., Groundwater. 53,4 (2015) 